\title{
Chemical features and bioactivities of cornflower (Centaurea cyanus L.) capitula: The blue flowers and the unexplored non-edible part
}

\author{
Lara Lockowandt ${ }^{\mathrm{a}, \mathrm{b}}$, José Pinela ${ }^{\mathrm{a}}$, Custódio Lobo Roriz ${ }^{\mathrm{a}}$, Carla Pereira ${ }^{\mathrm{a}}$, Rui M.V. Abreu ${ }^{\mathrm{a}}$, \\ Ricardo C. Calhelha ${ }^{\mathrm{a}}$, Maria José Alves ${ }^{\mathrm{a}}$, Lillian Barros ${ }^{\mathrm{a}}$, Michael Bredol ${ }^{\mathrm{b}}$, Isabel C.F.R. Ferreira ${ }^{\mathrm{a}, *}$ \\ ${ }^{a}$ Centro de Investigação de Montanha (CIMO), Instituto Politécnico de Bragança, Campus de Santa Apolónia, 5300-253, Bragança, Portugal \\ ${ }^{\mathrm{b}}$ Münster University of Applied Sciences, Department of Chemical Engineering, Stegerwaldstr. 39, 48-565, Steinfurt, Germany
}

\section{A R T I C L E I N F O}

\section{Keywords:}

Centaurea cyanus L.

Cornflower capitula

Phenolic compounds

Anthocyanins

Antioxidant activity

Antibacterial activity

\begin{abstract}
A B S T R A C T
Cornflower is a flowering weed and ornamental plant whose blue flowers have been used for food, decorative and colouring purposes. In this study, the upper (edible flowers) and lower (non-edible receptacle and involucre) parts of the capitulum were studied and compared for their chemical composition and bioactive properties. The flowers were richer in tocopherols, organic acids, and apigenin derivatives (mainly apigenin-7-O-glucuronide-4'$O$-(6-O-malonylglucoside)) than the non-edible bristly part (where syringic acid predominated). Four cyanidin derivatives were identified in the flowers. The extract of the non-edible part was more efficient in inhibiting the formation of thiobarbituric acid reactive substances (TBARS), the bleaching of $\beta$-carotene, and the haemolysis of the erythrocytes membrane. In general, the extracts were more active against Gram-positive bacteria and had no cytotoxicity against non-tumour liver PLP2 cells. Therefore, while flowers are a potential source of natural cyanidin-based colorants, the lower part of the capitulum has bioactive properties to be exploited in different food or pharmaceutical formulations.
\end{abstract}

\section{Introduction}

Centaurea cyanus L. (syn. Cyanus segetum Hill) is an annual Asteraceae species that grows in many countries throughout Europe and Asia (Hellwig, 2004). This flowering weed is commonly known as "cornflower" or "bachelors button" and often noticeable next to cornfields due to an intensive blue colour provided by a supramolecular pigment called protocyanin (Kondo et al., 1998). This pigment is in fact a metalloanthocyanin-complex formed by an anthocyanin, a flavone, $\mathrm{Fe}^{3+}$ and $\mathrm{Mg}^{2+}$ in the stoichiometric order 6:6:1:1. The anthocyanin in the complex has been identified as cyanidin-3-O-(6-O-succinylglucoside)-5-O-glucoside, while apigenin-7-O-glucuronide-4'-O-(6-O-malonylglucoside) is the corresponding flavone (Kondo et al., 1998; Takeda, 2006). These molecules are bound through metal complexation as well as hydrophobic interactions regarding anthocyanins and flavones. Since these bonds are quite weak, the protocyanin only exhibits a very stable blue colour in concentrated solutions; as soon as it is diluted, the colour fades (Yoshida et al., 2009).

Anthocyanins and flavones are phenolic compounds with hydrogendonating properties through one of the hydroxyl-groups. This makes them compounds with a high antioxidant potential, capable of acting as a counterpart towards the production of reactive oxygen species (ROS) (Martins et al., 2016). The human body produces ROS through normal metabolism. They can show an effective defence against infections and take part in cellular signalling pathways. However, once an overproduction of these reactive species occurs, the effects become detrimental as they attack free lipids and DNA (Valko et al., 2007). Next to the fact that the accumulation of DNA damage has shown to be one of the major reasons for aging, the influence of ROS on the normal cell functioning is responsible for many degenerative diseases like cardiovascular disease, diabetes, and different types of cancer (Reuter et al., 2010). Since free radicals are not only generated by normal metabolic process, but also through external factors like pollution, radiation or smoking, it quickly comes to an overproduction and so called oxidative stress (Reuter et al., 2010).

Facing this challenge, a diet that includes foods and supplements with antioxidant activity can function as a preventive medicine (Pinela et al., 2012b). One of the propagating factors for an enhanced research in this field was the so-called "French paradox", which showed that people with a moderate red-wine consumption wouldn't suffer from heart disease despite a fat based diet (Renaud and de Lorgeril, 1992). Results of this investigation led to anthocyanins and other polyphenols

\footnotetext{
* Corresponding author.

E-mail address: iferreira@ipb.pt (I.C.F.R. Ferreira).
} 
as strong bioactive compounds. Due to this fact and also to the colouring capacity, anthocyanins are already used as natural colorants with health promoting capacity in foodstuff (Roriz et al., 2018). But it's not only in this sector that the interest for natural colorants and bioactives is growing. Health awareness and lifestyle of today's society are changing towards an earlier lifestyle with a focus on natural products (Pires et al., 2018; Rop et al., 2012).

The present study faces a detailed characterisation of the cornflower capitula. While the blue flowers find a great interest as a potential source of natural colouring agents, as well as in food preparation deriving for example from an increasing popularity in garnishing dishes (Pires et al., 2018; Rop et al., 2012), the receptacle and involucre (nonedible bristly part) is a unexplored by-product of no commercial value. However, it may be an interesting source of bioactive compounds to be used in the development of functional foods, nutraceuticals, or pharmaceutical formulations. For that matter, the blue flowers were analysed separately from the non-edible lower part of the capitulum.

Until now some studies have been performed to characterize the flower pigments. A good summary about the historical development in research about the blue flower colour is presented by Yoshida et al. (2009). Reports regarding the evaluation of the bioactive potential of flower or capitulum extracts also exist from different authors (Escher et al., 2018; Garbacki et al., 1999; Marian et al., 2017; Pires et al., 2018). However, as far as we know, no studies describing the bioactive potential of the non-edible receptacle and involucre separately from the flowers exist in the literature. Therefore, this study was performed to characterize and compare the profiles in organic acids, tocopherols and phenolic compounds, including anthocyanins, of the blue flowers and non-edible lower part of the cornflower capitula, as well as to evaluate the antioxidant, antihaemolytic, anti-proliferative and antimicrobial properties of these plant parts.

\section{Material and methods}

\subsection{Plant samples}

Fresh cornflower samples were purchased from "Blumen Lennartz", a flower shop in Münster, Germany. The tubular blue flowers (edible part) of the capitulum (or flower head) were first separated from the non-edible part corresponding to the bristly receptacle and imbricated involucre, and separately processed. Then, both samples were lyophilized (Free Zone 4.5, Labconco, Kansas City, MO, USA), reduced to fine powder (20 mesh), and kept at $-20^{\circ} \mathrm{C}$ until analysis. It should be noted that some authors refer to flowers as being petals (Escher et al., 2018; Pires et al., 2018, 2017). This misunderstanding is due to the fact that the tubular flowers in the central part of the capitulum structure of this Asteraceae plant resemble single petals. Therefore, when discussing these works, we considered the analysed part as being the flowers.

\subsection{Analysis of organic acids}

The powdered samples $(\sim 200 \mathrm{mg})$ were stirred with metaPhosphoric acid $(4.5 \%$; $5 \mathrm{~mL})$ for 20 min protected from the light, and filtered first through filter paper (Whatman No. 4) and then through a $0.2-\mu \mathrm{m}$ nylon filter. The analysis was performed by ultra-fast liquid chromatography (Shimadzu 20 A series UFLC, Shimadzu Corporation, Kyoto, Japan) coupled to a photodiode array detector (PDA), operating in the conditions previously described by Pereira et al. (2013a, 2013b). Chromatographic separation was achieved in reverse phase with a $\mathrm{C}_{18}$ column ( $5 \mu \mathrm{m}$ particle size, $250 \times 4.6 \mathrm{~mm}$; Phenomenex, Torrance, CA, USA). The elution was performed with sulphuric acid $(3.6 \mathrm{mM})$. The compounds were identified and quantified by comparing the area of the sample' peaks recorded at $215 \mathrm{~nm}$ or $245 \mathrm{~nm}$ (for ascorbic acid) with calibration curves obtained from commercial standards (Sigma-Aldrich, St. Louis, MO, USA). The results were recorded and processed using LabSolutions Multi LC-PDA software (Shimadzu Corporation, Kyoto,
Japan) and expressed in $g$ per $100 \mathrm{~g}$ of plant dry weight (dw).

\subsection{Analysis of tocopherols}

Tocopherols were determined following a procedure previously described by Barros et al. (2013), using a HPLC system (Knauer, Smartline system 1000, Berlin, Germany) coupled to a fluorescence detector (FP-2020; Jasco, Easton, MD, USA) programmed for excitation at $290 \mathrm{~nm}$ and emission at $330 \mathrm{~nm}$, and the internal standard (tocol, Matreya, Pleasant Gap, PA, USA) method for quantification. Chromatographic separation was performed in normal-phase with a Polyamide II column $(5 \mu \mathrm{m}$ particle size, $250 \times 4.6 \mathrm{~mm}$; YMC, Kyoto, Japan). Elution was performed with a mixture of $n$-hexane and ethyl acetate (70:30, v/v; HPLC grade, Lab-Scan, Lisbon, Portugal). The results were recorded and processed using Clarity 2.4 software (DataApex, Prague, Czech Republic) and expressed in mg per $100 \mathrm{~g}$ of plant dry weight (dw).

\subsection{Preparation of hydromethanolic extracts}

The powdered samples $(\sim 1 \mathrm{~g})$ were subjected to a solid-liquid extraction with a methanol/water mixture $(80: 20, \mathrm{v} / \mathrm{v} ; 30 \mathrm{~mL})$. Acidified solvent $(0.05 \%$ trifluoroacetic acid) was used for the flower samples. The extraction was performed at $25^{\circ} \mathrm{C}$ and $150 \mathrm{rpm}$ during $1 \mathrm{~h}$, followed by filtration through filter paper (Whatman No. 4). Afterwards, the extraction procedure was repeated with the residue. In case of the flower sample, the extraction was repeated up to five times until the residue lost all colour. The combined extracts were then concentrated under reduced pressure at $40^{\circ} \mathrm{C}$ (rotary evaporator Büchi R-210, Flawil, Switzerland) and the aqueous phase was lyophilised. The dried extracts were kept in the best conditions until further analysis.

\subsection{Analysis of phenolic compounds}

The dried extracts were re-dissolved in water/methanol (80:20, v/v) at $10 \mathrm{mg} / \mathrm{mL}$ and filtered through a $0.22-\mu \mathrm{m}$ disposable LC filter disk. The analysis was performed by high performance liquid chromatography coupled to a diode array detector and electrospray ionization tandem mass spectrometry (HPLC-DAD-ESI/MS ${ }^{\mathrm{n}}$; Dionex Ultimate 3000 UPLC, Thermo Scientific, San Jose, CA, USA). Chromatographic separation was achieved in reverse phase with a $\mathrm{C}_{18}$ column $(3 \mu \mathrm{m}$ particle size, $4.6 \mathrm{~mm} \times 150 \mathrm{~mm}$; Waters Spherisorb S3 ODS-2) for nonanthocyanin compounds and in a AQUA ${ }^{\circledast}$ (Phenomenex) reverse phase $\mathrm{C}_{18}$ column $(5 \mu \mathrm{m}, 150 \mathrm{~mm} \times 4.6 \mathrm{~mm}$ i.d) for anthocyanin compounds. Non-anthocyanin compounds were eluted with formic acid $(0.1 \%)$ (Sigma-Aldrich, St. Louis, MO, USA) in water (A) and acetonitrile (B) (HPLC grade, Fisher Scientific, Lisbon, Portugal) (Bessada et al., 2016), while $0.1 \%$ trifluoroacetic acid (TFA) in water (A) and acetonitrile (B) were used for anthocyanins (Gonçalves et al., 2017). The compounds identification was performed in double online detection using DAD (280, 330 and $370 \mathrm{~nm}$, or $520 \mathrm{~nm}$ for anthocyanins) coupled to a mass spectrometer equipped with an ESI source (Linear Ion Trap LTQ XL mass spectrometer; Thermo Finnigan, San Jose, CA, USA), working in negative mode for non-anthocyanin compounds, and positive mode for anthocyanin compounds. Identification was performed comparing the fragmentation pattern, retention times and UV-vis spectra with authentic standards (Extrasynthèse, Genay, France) or available data from literature. Quantification was achieved with the calibration curve of the correspondent phenolic standard or, if not available, with a similar compound of the same group. The results were recorded and processed using Xcalibur data system (Thermo Finnigan, San Jose, CA, USA) and expressed in mg per $g$ of extract (for non-anthocyanin compounds) or $\mathrm{mg}$ per $\mathrm{g}$ of extract (for anthocyanins). 


\subsection{Evaluation of bioactive properties}

\subsubsection{Antioxidant activity}

The antioxidant capacity of the extracts was evaluated following two in vitro assays previously described by Pinela et al., (2012a, 2012b): i) $\beta$-carotene bleaching inhibition capacity in the presence of linoleic acid free radicals; and ii) thiobarbituric acid reactive substances (TBARS) formation inhibition capacity in brain cell homogenates. Trolox (Sigma-Aldrich, St. Louis, MO, USA) was used as positive control. The results were expressed in $\mathrm{EC}_{50}$ values $(\mu \mathrm{g} / \mathrm{mL})$, i.e., extract concentration providing $50 \%$ of antioxidant activity.

\subsubsection{Antihaemolytic activity}

The antihaemolytic activity of the extracts was evaluated by the oxidative haemolysis inhibition assay (OxHLIA) described previously by Takebayashi et al. (2012) with some modifications. Sheep blood samples were collected from healthy animals and centrifuged at $1000 \mathrm{~g}$ for $5 \mathrm{~min}$ at $10^{\circ} \mathrm{C}$. Plasma and buffy coats were discarded and erythrocytes were first washed once with $\mathrm{NaCl}(150 \mathrm{mM})$ and three times with phosphate-buffered saline (PBS, pH 7.4) (Evans et al., 2013). The erythrocyte pellet was then resuspended in PBS at $2.8 \%(\mathrm{v} / \mathrm{v})$. Using a flat bottom 48-well microplate, $200 \mu \mathrm{L}$ of erythrocyte solution was mixed with $400 \mu \mathrm{L}$ of either PBS solution (control), antioxidant sample dissolved in PBS, or water (for complete haemolysis). Trolox was used as positive control. After pre-incubation at $37^{\circ} \mathrm{C}$ for $10 \mathrm{~min}$ with shaking, 2,2'-azobis(2-methylpropionamidine) dihydrochloride (AAPH, $160 \mathrm{mM}$ in PBS, $200 \mu \mathrm{L}$ ) was added and the optical density was measured at $690 \mathrm{~nm}$. After that, the microplate was incubated under the same conditions and the optical density was measured every $10 \mathrm{~min}$ at the same wavelength for approximately $400 \mathrm{~min}$ (Takebayashi et al., 2012). The percentage of the erythrocyte population that remained intact $(P)$ was calculated according to Eq. (1).

$\mathrm{P}(\%)=\left(\mathrm{S}_{\mathrm{t}}-\mathrm{CH}_{0} / \mathrm{S}_{0}-\mathrm{CH}_{0}\right) \times 100$

where $\mathrm{S}_{\mathrm{t}}$ and $\mathrm{S}_{0}$ correspond to the optical density of the sample at $t$ and $0 \mathrm{~min}$, respectively, and $\mathrm{CH}_{0}$ is the optical density of the complete haemolysis at $0 \mathrm{~min}$. The results were expressed as delayed time of haemolysis $(\Delta \mathrm{t})$, which was calculated according to Eq. (2).

$\Delta \mathrm{t}(\min )=\mathrm{Ht}_{50}($ sample $)-\mathrm{Ht}_{50}($ control $)$

where $\mathrm{Ht}_{50}$ is the $50 \%$ haemolytic time ( $\mathrm{min}$ ) graphically obtained from the haemolysis curve of each antioxidant sample concentration. The $\Delta \mathrm{t}$ values were then correlated to antioxidant sample concentrations (Takebayashi et al., 2012) and, from the correlation obtained, the extract concentration able to promote a $\Delta \mathrm{t}$ haemolysis delay was calculated. The results were given as $\mathrm{IC}_{50}$ values $(\mu \mathrm{g} / \mathrm{mL})$ at $\Delta \mathrm{t} 60$ and 120 min, i.e., extract concentration required to keep $50 \%$ of the erythrocyte population intact for 60 and $120 \mathrm{~min}$.

\subsubsection{Anti-proliferative activity}

The anti-proliferative capacity of the extracts was evaluated by the sulforhodamine B (Sigma-Aldrich, St. Louis, MO, USA) assay against four human tumour cell lines (acquired from Leibniz-Institut DSMZ): MCF-7 (breast adenocarcinoma), NCI-H460 (non-small cell lung cancer), HeLa (cervical carcinoma), and HepG2 (hepatocellular carcinoma), as previously described by Vaz et al. (2010). Ellipticine (SigmaAldrich, St. Louis, MO, USA) was used as positive control. The results were expressed in $\mathrm{GI}_{50}$ values $(\mu \mathrm{g} / \mathrm{mL})$, i.e. extract concentration providing $50 \%$ of cell growth inhibition.

\subsubsection{Hepatotoxicity}

The sulforhodamine B assay was also performed to evaluated the hepatotoxicity of the extracts against a non-tumour cell line (PLP2, porcine liver primary cells). The procedure for obtaining and maintaining the cell line were previously described by Pereira et al. (2013a, 2013b). Ellipticine was used as positive control. The results were expressed in $\mathrm{GI}_{50}$ values $(\mu \mathrm{g} / \mathrm{mL})$.

\subsubsection{Antibacterial activity}

The extracts were screened against five Gram-negative bacteria (Escherichia coli, Klebsiella pneumoniae, Morganella morganii, Pseudomonas aeruginosa and Proteus mirabilis) and four Gram-positive bacteria (methicillin-resistant Staphylococcus aureus (MRSA), methicillin-susceptible Staphylococcus aureus (MSSA), Listeria monocytogenes and Enterococcus faecalis) (clinical isolates of patients from hospital units in North-eastern Portugal). The microdilution method and the rapid $p$-iodonitrotetrazolium chloride (INT; Panreac Applichem, Barcelona, Spain) colorimetric assay were performed following the methodology described by Pires et al. (2018) with some modifications. For each inoculum, one positive control was prepared with bacteria and Mueller-Hinton broth (MHB; Biolab, Budapest, Hungary). Three negative controls were also prepared, one with MHB or tryptic soy broth (TSB; Biolab, Budapest, Hungary), one with the extract only, and the last one with medium and antibiotic (vancomycin, imipenem and ampicillin). The results were given as minimum inhibitory concentrations (MICs, $\mathrm{mg} / \mathrm{mL}$ ), i.e., the lowest extract concentration that inhibits the visible bacterial growth.

\subsection{Statistical analysis}

The experiments were carried out in triplicate and the results were expressed as mean \pm standard deviation. SPSS Statistics software (IBM SPSS Statistics for Windows, Version 22.0. Armonk, NY: IBM Corp.) was used to analyse differences among the two samples by applying a twotailed paired Student's $t$-test at a $5 \%$ significance level. Significant differences between the samples were considered when the $p$-value was lower than 0.05 .

\section{Results and discussion}

\subsection{Composition in organic acids}

Organic acids accumulate in plant tissues as intermediates in the photosynthetic process. They influence various biochemical pathways, such as the production of energy and formation of precursors for amino acids biosynthesis. Generally, their task is the support of the plant to adapt to environmental changes (Igamberdiev and Bykova, 2018). In plant foods, these organic compounds affect the taste, namely sourness, and confer antimicrobial and preservative properties (citric acid, for example, is a widely used food additive). When ingested, they facilitate digestion, help stabilise water-soluble vitamins, and improve the absorption of $\mathrm{K}, \mathrm{Cu}, \mathrm{Zn}$, and Ca (Ghnimi et al., 2018; López-Bucio et al., 2000; Ornelas-Paz et al., 2013).

Table 1 presents the organic acids found in the flowers and nonedible lower part of the cornflower capitula. Oxalic, quinic, malic, shikimic, citric, succinic and fumaric acids were identified in both parts of the capitulum. The flowers had a higher amount of total organic acids than the non-edible part, with $6.63 \pm 0.03 \mathrm{~g} / 100 \mathrm{~g} \mathrm{dw}$ and $5.3 \pm 0.2 \mathrm{~g} / 100 \mathrm{~g} \mathrm{dw}$, respectively. Succinic acid was the most abundant organic acid in flowers and non-edible parts $(2.55 \pm 0.01 \mathrm{~g} / 100 \mathrm{~g}$ $\mathrm{dw}$ and $1.87 \pm 0.06 \mathrm{~g} / 100 \mathrm{~g} \mathrm{dw}$, respectively), followed by citric $(2.29 \pm 0.03 \mathrm{~g} / 100 \mathrm{~g} \mathrm{dw})$ and quinic $(1.51 \pm 0.05 \mathrm{~g} / 100 \mathrm{~g} \mathrm{dw})$ acids, respectively. The high amounts of citric, succinic and quinic acids observed in these inflorescence parts may derive from their involvement in the central energy-yielding cycle of the cell, the so-called Krebs cycle (Vigani et al., 2018). In these flowers, succinic acid may appear as a succinyl moiety attached to the sugar of the predominant anthocyanin (cyanidin-3-O-(6-O-succinylglucoside)-5-O-glucoside) found in the colour-giving complex called protocyanin (Yoshida et al., 2009).

In a previous study, Pires et al. (2017) found slightly lower amounts of oxalic $(0.18 \mathrm{~g} / 100 \mathrm{~g})$ and shikimic $(0.108 \mathrm{~g} / 100 \mathrm{~g})$ acids and just 
Table 1

Composition in organic acids and tocopherols of the flowers and non-edible lower part of the cornflower capitula.

\begin{tabular}{|c|c|c|c|}
\hline & Flowers & Non-edible part & Statistics $^{\mathrm{a}}$ \\
\hline Organic acids $(g / 100 g d w)$ & & & $p$-value \\
\hline Oxalic acid & $0.36 \pm 0.01$ & $0.265 \pm 0.002$ & $<0.001$ \\
\hline Quinic acid & $0.93 \pm 0.03$ & $1.51 \pm 0.05$ & $<0.001$ \\
\hline Malic acid & $0.36 \pm 0.01$ & $0.251 \pm 0.001$ & $<0.001$ \\
\hline Shikimic acid & $0.141 \pm 0.002$ & $0.062 \pm 0.002$ & $<0.001$ \\
\hline Citric acid & $2.29 \pm 0.03$ & $1.37 \pm 0.04$ & $<0.001$ \\
\hline Succinic acid & $2.55 \pm 0.01$ & $1.87 \pm 0.06$ & $<0.001$ \\
\hline Fumaric acid & $0.0021 \pm 0.0001$ & $\operatorname{tr}$ & - \\
\hline Total organic acids & $6.63 \pm 0.03$ & $5.3 \pm 0.2$ & $<0.001$ \\
\hline \multicolumn{4}{|l|}{ Tocopherols $(\mathrm{mg} / 100 \mathrm{~g} \mathrm{dw})$} \\
\hline$\alpha$-Tocopherol & $1.01 \pm 0.01$ & $0.511 \pm 0.002$ & $<0.001$ \\
\hline$\beta$-Tocopherol & nd & nd & - \\
\hline$\gamma$-Tocopherol & $0.290 \pm 0.001$ & $0.097 \pm 0.002$ & $<0.001$ \\
\hline$\delta$-Tocopherol & nd & nd & - \\
\hline Total tocopherols & $1.30 \pm 0.01$ & $0.607 \pm 0.003$ & $<0.001$ \\
\hline
\end{tabular}

tr: traces; nd: not detected.

a Statistical differences $(p<0.05)$ were assessed by applying a two-tailed paired Student's $t$-test.

traces of fumaric acid in dried flowers of cornflower. However, the authors did not detect any of the other compound herein reported. These differences could derive from the fact that organic acids play an important role in the adaption of plants to the environment and also from variations in the edaphoclimatic conditions of the growing sites (e.g., soil composition, water availability, and sunlight exposure), which may influence the formation of these compounds (Igamberdiev and Bykova, 2018; López-Bucio et al., 2000).

\subsection{Composition in tocopherols}

The tocopherol contents quantified in the two distinct parts of the cornflower capitulum are given in Table 1. Only the $\alpha$ - and $\gamma$-isoforms were found in both samples, in accordance with previous studies (Pires et al., 2017). It is noticeable that the values for total tocopherols in the flower $(1.30 \pm 0.01 \mathrm{mg} / 100 \mathrm{~g} \mathrm{dw})$ are about twice as high as the ones in the sample constituted by the receptacle and involucre (0.607 $\pm 0.003 \mathrm{mg} / 100 \mathrm{~g} \mathrm{dw}$ ). Pires et al. (2017) reported comparable tocopherol profile for other flowering plants, namely rose (Rosa canina L.) petals and calendula (Calendula officinalis L.) flowers, where $\alpha$-tocopherol was the major isoform. Nevertheless, the total tocopherol contents were much higher than those found in our samples, ranging from $9.25 \pm 0.04 \mathrm{mg} / 100 \mathrm{~g} \mathrm{dw}$ in the rose petals to $60.88 \pm 0.92 \mathrm{mg} /$ $100 \mathrm{~g} \mathrm{dw}$ in the calendula flowers.

The consumption of foods rich in this fat-soluble vitamin (vitamin E) has been recommended by health professionals because tocopherols are powerful antioxidants capable of protecting cells from the damaging effects of ROS. The recommended dietary allowances (RDAs) of $15 \mathrm{mg} /$ day (as $\alpha$-tocopherol) are established for 14 or more years old individuals (NIH, 2018). Therefore, a $100 \mathrm{~g}$ portion of the edible flower dry weight of cornflower provides $6.73 \%$ of the RDA for this vitamin.

\subsection{Composition in phenolic compounds}

The solid-liquid extraction used to prepare the hydromethanolic extracts yielded about $40 \%$ for the flowers and $23 \%$ for the non-edible part of the capitulum. However, it should be noted that the extraction procedure was repeated up to five times for the flower sample (until no colour appearance), while the non-edible part was only extracted twice. The phenolic compounds identified in these extracts are presented in Table 2. These compounds were identified based on the retention time (Rt), maximum absorbance wavelength $\left(\lambda_{\max }\right)$, pseudomolecular ion $\left([\mathrm{M}-\mathrm{H}]^{-}\right)$, and corresponding fragmentation pattern $\left(\mathrm{MS}^{2}\right)$. Four phenolic acid derivatives (chlorogenic, $p$-coumaric, caffeic, and syringic acids), 12 non-anthocyanin flavonoids (mostly apigenin derivatives, but also quercetin, kaempferol, eriodictyol and taxifolin derivatives), and 4 anthocyanins (cyanidin derivatives) were identified in the cornflower capitulum, namely in the extracts prepared from the flowers and the receptacle plus involucre. The HPLC profiles of phenolic compounds of the upper (blue flowers) and lower (bristly receptacle and imbricated involucre) parts of cornflower capitula are shown in Fig. 1.

\subsubsection{Phenolic acids}

The phenolic acids were more abundant in the non-edible part $(5.5 \pm 0.002 \mathrm{mg} / \mathrm{g}$ extract $)$ than in the flowers $(0.134 \pm 0.003 \mathrm{mg} / \mathrm{g}$ extract) of the cornflower capitulum. Comparable amounts were reported by Pires et al. (2018) in a hydromethanolic extract of dried flowers $(0.16 \pm 0.03 \mathrm{mg} / \mathrm{g})$. Peak 2 was tentatively identified as $5-\mathrm{O}$ caffeoylquinic acid (chlorogenic acid), having been quantified in the ranges of $0.134 \pm 0.002 \mathrm{mg} / \mathrm{g}$ and $0.162 \pm 0.003 \mathrm{mg} / \mathrm{g}$, in the flower and non-edible part extracts, respectively (Table 2). This compound was also reported in a previous study performed by Pires et al. (2018) $(0.12 \pm 0.01 \mathrm{mg} / \mathrm{g})$ and Escher et al. (2018) $(39.0 \pm 0.5 \mathrm{mg} / \mathrm{g})$. In addition, this was the only phenolic acid found in the flower extract, which has been correlated with several biological effects, including antioxidant and anti-proliferative activities (Naso et al., 2014). Peak 3 was assigned to a p-coumaric acid hexoside, with a pseudomolecular ion $[\mathrm{M}-\mathrm{H}]^{-}$at $m / z 325$ and a fragmenting pattern at $m / z 163(-162 \mathrm{u}$, loss of hexosyl moiety). Although this compound has already been identified in the flowers of this plant (Pires et al., 2018), here it was only found in the non-edible part of the capitulum. Caffeic acid was identified by comparison with a commercial standard; while $0.107 \pm 0.004 \mathrm{mg} / \mathrm{g}$ were detected in the extract of the non-edible sample, Escher et al. (2018) reported $0.016 \pm 0.001 \mathrm{mg} / \mathrm{g}$ in an aqueous flower extract acidified with acetic acid ( $0.545 \mathrm{~mol} / \mathrm{L}, \mathrm{pH} 2.5)$. Syringic acid was the most abundant phenolic compound found in the non-edible part, reaching $5.070 \pm 0.002 \mathrm{mg} / \mathrm{g}$ extract. It showed an absorption maximum at $280 \mathrm{~nm}$, a pseudomolecular ion $[\mathrm{M}-\mathrm{H}]^{-}$at $m /$ z 197 and a $\mathrm{MS}^{2}$ fragment at $\mathrm{m} / z 121$ (Table 2), and was positively identified in comparison with a commercial standard. This compound was not detected in the flower extract analysed in this study, neither in those of Escher et al. (2018) and Pires et al. (2018).

\subsubsection{Non-anthocyanin flavonoids}

The total content of non-anthocyanin flavonoids (sum of the quantified flavones, flavonols, flavanones and flavanonols) was higher in the flower extract $(10.7 \pm 0.02 \mathrm{mg} / \mathrm{g})$ than in that prepared from the nonedible lower part $(6.80 \pm 0.01 \mathrm{mg} / \mathrm{g})$ of the capitulum, contrary to that observed for phenolic acids.

The flavone apigenin was the most abundant flavonoid in the capitula, with the unique $\mathrm{MS}^{2}$ fragment at $m / z 269$, which was recognized in the peaks 7, 9-12, 15, and 17 (Table 2). Among these, peak 9 was the major one (with $5.5 \pm 0.1 \mathrm{mg} / \mathrm{g}$ of flower extract), showing a pseudomolecular ion $[\mathrm{M}-\mathrm{H}]^{-}$at $m / z$ 693. The revealed fragmentation pattern indicated a loss of $\mathrm{CO}_{2}$ from the malonyl-moiety $(44 \mathrm{u})$, followed by a loss of a glucuronide (176 u) and a hexosyl with the rest of the malonyl moiety $\left(\mathrm{C}_{2} \mathrm{H}_{2} \mathrm{O}\right)(204 \mathrm{u}=162 \mathrm{u}+42 \mathrm{u})$. In combination with the UV-spectrum and information from literature, describing apigenin-7-O-glucuronide-4'-O-(6-O-malonylglucoside) as the flavone in protocyanin (Yoshida et al., 2009), the compound was tentatively identified as the mentioned compound. The following two peaks, 10 and 11 , showed a very similar absorbance spectrum and the same fragmentation pattern as peak 9 (Table 2). Therefore, they have been identified as apigenin- $O$-glucuronide- $O$-malonylhexoside isomers; however, the different retention times could indicate a variation in the position of the glucuronide or malonylhexoside moieties.

Peak 12 was identified as apigenin-7-O-glucoside by comparison with a commercial standard. Peaks $15\left([\mathrm{M}-\mathrm{H}]^{-}\right.$at $\left.m / z 445\right)$ and 17 $\left([\mathrm{M}-\mathrm{H}]^{-}\right.$at $m / z$ 473) were tentatively identified as apigenin-O-glucuronide and apigenin- $\mathrm{O}$-acetylhexoside taking into account their 
Table 2

Retention time (Rt), wavelengths of maximum absorption in the UV-vis region ( $\left.\lambda_{\max }\right)$, pseudomolecular and $\mathrm{MS}^{2}$ fragment ions (in brackets, relative abundance), tentative identification, and quantification of phenolic compounds in the extracts of the flowers and non-edible lower part of the cornflower capitula.

\begin{tabular}{|c|c|c|c|c|c|c|c|c|}
\hline \multirow[t]{2}{*}{ Peak } & \multirow[t]{2}{*}{ Rt (min) } & \multirow{2}{*}{$\begin{array}{l}\lambda_{\max } \\
(\mathrm{nm})\end{array}$} & \multirow{2}{*}{$\begin{array}{l}{[\mathrm{M}-\mathrm{H}]^{-}(m /} \\
z)\end{array}$} & \multirow[t]{2}{*}{$\mathrm{MS}^{2}$ fragments $(\mathrm{m} / \mathrm{z})$} & \multirow[t]{2}{*}{ Tentative identification } & \multicolumn{2}{|l|}{ Quantification } & \multirow{2}{*}{$\begin{array}{l}\text { Statistics } \\
p \text {-value }\end{array}$} \\
\hline & & & & & & Flowers & Non-edible part & \\
\hline \multicolumn{6}{|c|}{ Non-anthocyanin compounds } & \multicolumn{3}{|c|}{ Content in $\mathrm{mg} / \mathrm{g}$ extract } \\
\hline 1 & 5.1 & 263 & 627 & 465(100), 303(3), 285(3) & Taxifolin-O-dihexoside ${ }^{\mathrm{E}}$ & $1.31 \pm 0.02$ & nd & - \\
\hline 2 & 6.8 & 321 & 353 & $\begin{array}{l}\text { 191(100), 179(10), 161(3), } \\
135(5)\end{array}$ & 5-O-Caffeoylquinic acid (chlorogenic acid) ${ }^{\mathrm{C}}$ & $0.134 \pm 0.002$ & $0.162 \pm 0.003$ & $<0.001$ \\
\hline 3 & 7.5 & 313 & 325 & $163(100)$ & $p$-Coumaric acid hexoside ${ }^{\mathrm{F}}$ & nd & $0.21 \pm 0.01$ & - \\
\hline 4 & 9.2 & 268,330 & 449 & $287(100)$ & Eriodictyol-O-hexoside ${ }^{\mathrm{C}}$ & nd & $0.13 \pm 0.01$ & - \\
\hline 5 & 9.9 & 320 & 179 & $135(100)$ & Caffeic $\operatorname{acid}^{\mathrm{B}}$ & nd & $0.107 \pm 0.004$ & - \\
\hline 6 & 11.9 & 280 & 197 & $121(100)$ & Syringic acid ${ }^{\mathrm{G}}$ & nd & $5.070 \pm 0.002$ & - \\
\hline 7 & 13.3 & 320 & 607 & $445(89), 431(100), 269(47)$ & Apigenin- $O$-hexoside- $O$-glucuronide ${ }^{\mathrm{A}}$ & $1.77 \pm 0.02$ & $0.87 \pm 0.01$ & $<0.001$ \\
\hline 8 & 16.5 & 266,344 & 609 & $285(100)$ & Kaempferol-O-dihexoside ${ }^{\mathrm{D}}$ & nd & $\operatorname{tr}$ & - \\
\hline 9 & 17.6 & 320 & 693 & $\begin{array}{l}\text { 649(100), 473(52), 445(20), } \\
269(10)\end{array}$ & $\begin{array}{l}\text { Apigenin-7-O-glucuronide-4'-O-(6-O- } \\
\text { malonylglucoside })^{\mathrm{A}}\end{array}$ & $5.5 \pm 0.1$ & $1.133 \pm 0.003$ & $<0.001$ \\
\hline 10 & 18.0 & 319 & 693 & $\begin{array}{l}\text { 649(100), 473(52), 445(20), } \\
269(10)\end{array}$ & $\begin{array}{l}\text { Apigenin- } O \text {-glucuronide- } O \text {-(malonylhexoside) } \\
\text { isomer } 1^{\mathrm{A}}\end{array}$ & nd & $0.83 \pm 0.02$ & - \\
\hline 11 & 19.0 & 320 & 693 & $\begin{array}{l}\text { 649(100), 473(52), 445(20), } \\
\text { 269(10) }\end{array}$ & $\begin{array}{l}\text { Apigenin-O-glucuronide- } O \text {-(malonylhexoside) } \\
\text { isomer } 2^{\mathrm{A}}\end{array}$ & $0.83 \pm 0.02$ & $0.831 \pm 0.003$ & 0.799 \\
\hline 12 & 19.6 & 320 & 431 & $269(100)$ & Apigenin-7-O-glucoside ${ }^{\mathrm{A}}$ & $0.63 \pm 0.02$ & nd & - \\
\hline 13 & 20.3 & 350 & 505 & 463(27), 301(100) & Quercetin-3-O-(6"-acetyl)glucoside ${ }^{\mathrm{E}}$ & nd & $0.653 \pm 0.003$ & - \\
\hline 14 & 22.5 & 340 & 447 & $285(100)$ & Kaempferol-3-O-glucoside ${ }^{\mathrm{D}}$ & nd & $\operatorname{tr}$ & - \\
\hline 15 & 23.1 & 332 & 445 & $269(100)$ & Apigenin-O-glucuronide $^{\mathrm{A}}$ & $0.678 \pm 0.005$ & $1.770 \pm 0.003$ & $<0.001$ \\
\hline 16 & 24.7 & 335 & 489 & $285(100)$ & Kaempferol-O-acetylhexoside ${ }^{\mathrm{D}}$ & $\operatorname{tr}$ & $\operatorname{tr}$ & - \\
\hline 17 & 29.1 & 317 & 473 & $269(100)$ & Apigenin- $O$-acetylhexoside ${ }^{\mathrm{A}}$ & nd & $0.585 \pm 0.003$ & - \\
\hline \multicolumn{6}{|c|}{ Anthocyanin compounds } & \multicolumn{3}{|c|}{ Content in $\mathrm{mg} / \mathrm{g}$ extract } \\
\hline 18 & 13.19 & 515 & $611^{*}$ & 449(100), 287(32) & Cyanidin-3,5-di-O-glucoside ${ }^{\mathrm{H}}$ & $5.2 \pm 0.2$ & nd & - \\
\hline 19 & 20.47 & 514 & $697^{*}$ & 535(100), 449(5), 287(15) & $\begin{array}{l}\text { Cyanidin-3-O-(6"-malonylglucoside)-5-O- } \\
\text { glucoside }^{\mathrm{H}}\end{array}$ & $3.25 \pm 0.06$ & nd & - \\
\hline 20 & 21.51 & 514 & $449 *$ & $287(100)$ & Cyanidin-3-O-glucoside ${ }^{\mathrm{H}}$ & $2.89 \pm 0.05$ & nd & - \\
\hline \multirow[t]{5}{*}{21} & 23.39 & 514 & $711^{*}$ & 549(100), 449(8), 287(19) & $\begin{array}{l}\text { Cyanidin-3-O-(6"-succinylglucoside)-5-O- } \\
\text { glucoside } \mathrm{H}^{\mathrm{H}}\end{array}$ & $15.7 \pm 0.9$ & nd & - \\
\hline & & & & & Total phenolic acids & $0.134 \pm 0.003$ & $5.5 \pm 0.02$ & $<0.001$ \\
\hline & & & & & Total non-anthocyanin flavonoids & $10.7 \pm 0.2$ & $6.80 \pm 0.01$ & $<0.001$ \\
\hline & & & & & Total anthocyanins & $27 \pm 1$ & - & - \\
\hline & & & & & Total phenolic compounds & $38 \pm 1$ & $12.35 \pm 0.01$ & $<0.001$ \\
\hline
\end{tabular}

Standard calibration curves: A: apigenin-7-O-glucoside ( $\left.\mathrm{y}=10683 \mathrm{x}-45.794, R^{2}=0.991\right)$; B: caffeic acid (y $\left.=388345 \mathrm{x}+406.369, R^{2}=0.994\right)$; C: chlorogenic acid ( $\left.\mathrm{y}=168823 \mathrm{x}-161.172, R^{2}=0.9999\right)$; $\mathrm{D}$ : kaempferol-3-O-rutinoside (y $\left.=41843 \mathrm{x}+220.192, R^{2}=0.998\right)$; E: quercetin-3-O-glucoside ( $\mathrm{y}=34843 \mathrm{x}-160.173$, $\left.R^{2}=0.998\right) ; \mathrm{F}$ : $p$-coumaric acid $\left(\mathrm{y}=301950 \mathrm{x}+6966.7, R^{2}=0.9999\right) ; \mathrm{G}:$ syringic acid (y $\left.=376056 \mathrm{x}+141329, R^{2}=0.999\right) ; \mathrm{H}$ : cyanidin-3-O-glucoside $\left(\mathrm{y}=243287 \mathrm{x}-1 \mathrm{E}+06, \mathrm{R}^{2}=0.9953\right) .{ }^{*}[\mathrm{M}+\mathrm{H}]^{+}(m / z)$. nd: not detected; tr: traces.

a Statistical differences $(p<0.05)$ were assessed by applying a two-tailed paired Student's $t$-test.

fragmentations patter, revealing a glucuronide $(176 \mathrm{u})$ and acetylhexoside $(162 \mathrm{u}+42)$ moiety release, respectively. Peak $7\left([\mathrm{M}-\mathrm{H}]^{-}\right.$ at $m / z 607$ ) presented a similar absorption spectrum to the major peak, revealing two main fragments at $m / z 445$ (loss of hexosyl, $162 \mathrm{u}$ ) and 269 (loss of glucuronide, $176 \mathrm{u}$ ), and therefore was tentatively identified as apigenin-O-hexoside-O-glucuronide.

The apigenin derivatives described above were detected in greater quantity in the flowers $(\sim 9.41 \mathrm{mg} / \mathrm{g}$ extract $)$ than in the non-edible bristly part $(\sim 6.02 \mathrm{mg} / \mathrm{g}$ extract). All of them were detected in the nonedible part, while only 4 were found in the flowers. In a previous study, Pires et al. (2018) reported apigenin-glucuronide as the major phenolic compound in dried flower extracts $(\sim 12.22 \mathrm{mg} / \mathrm{g})$, and the existence of apigenin-glucuronide-acetylhexoside $(\sim 1.25 \mathrm{mg} / \mathrm{g})$. In contrast, apigenin was not detected by Escher et al. (2018) in a flower aqueous extract.

Moreover, trace amounts of flavonols were also identified in these extracts, being tentatively identified as kaempferol derivatives (Table 2). Peaks 8,14 and 16 revealed pseudomolecular ions $[\mathrm{M}-\mathrm{H}]^{-}$ at $m / z 609,447$ and 489, respectively, and were tentatively identified as kaempferol-O-dihexoside, kaempferol-3-O-glucoside (identified in comparison to the commercial standard) and kaempferol-O-acetylhexoside. Traces of the former compounds were also reported by Pires et al. (2018).

One flavanone was identified as eriodictyol-O-hexoside (peak 4), with a maximum absorbance at 268 and $330 \mathrm{~nm}$ (Table 2). This compound showed a pseudomolecular ion $[\mathrm{M}-\mathrm{H}]^{-}$at $m / z 449$ and the main fragment in $\mathrm{MS}^{2}$ at $m / z 287$ (corresponding to eriodictyol aglycone), and was only detected in the non-edible part of the capitulum $(0.13 \pm 0.01 \mathrm{mg} / \mathrm{g}$ extract $)$. This flavanone has already been identified in an hydromethanolic extract of dahlia (Dahlia mignon) flowers (disc florets) (Pires et al., 2018).

Peak $13\left([\mathrm{M}-\mathrm{H}]^{-}\right.$at $\left.m / z 505\right)$ was tentatively identified as quercetin-3-O-(6"-acetyl)glucoside. This flavonol was only found in the nonedible part $(0.653 \pm 0.003)$, although it has already been identified in a flower extract $(0.83 \pm 0.01 \mathrm{mg} / \mathrm{g})$, as well as another quercetin derivate called quercetin-hexoside-acetylhexoside (Pires et al., 2018).

Peak $1\left([\mathrm{M}-\mathrm{H}]^{-}\right.$at $\left.m / z 627\right)$ was tentatively identified as taxifolin$O$-dihexoside. This is in accordance with the analysis previously performed by Pires et al. (2018), which quantified interesting amounts $(\sim 3.12 \mathrm{mg} / \mathrm{g})$ of taxifolin (i.e., dihydroquercetin) derivatives in cornflower flowers. As presented in Table 2, $1.31 \pm 0.02 \mathrm{mg} / \mathrm{g}$ extract were found in the flower sample.

\subsubsection{Anthocyanins}

The anthocyanins profile of the acidified hydromethanolic extract of the blue flowers of cornflower is shown in Fig. 1. Four cyanidin derivatives were identified and quantified (Table 2). All these compounds had an absorption maximum around $515 \mathrm{~nm}$. The main compound (peak 21) presented a pseudomolecular ion $[\mathrm{M}+\mathrm{H}]^{+}$at $m / z 711$. The ion released one major fragment in $\mathrm{MS}^{2}$ at $\mathrm{m} / \mathrm{z} 549$ (loss $162 \mathrm{u}$, a 

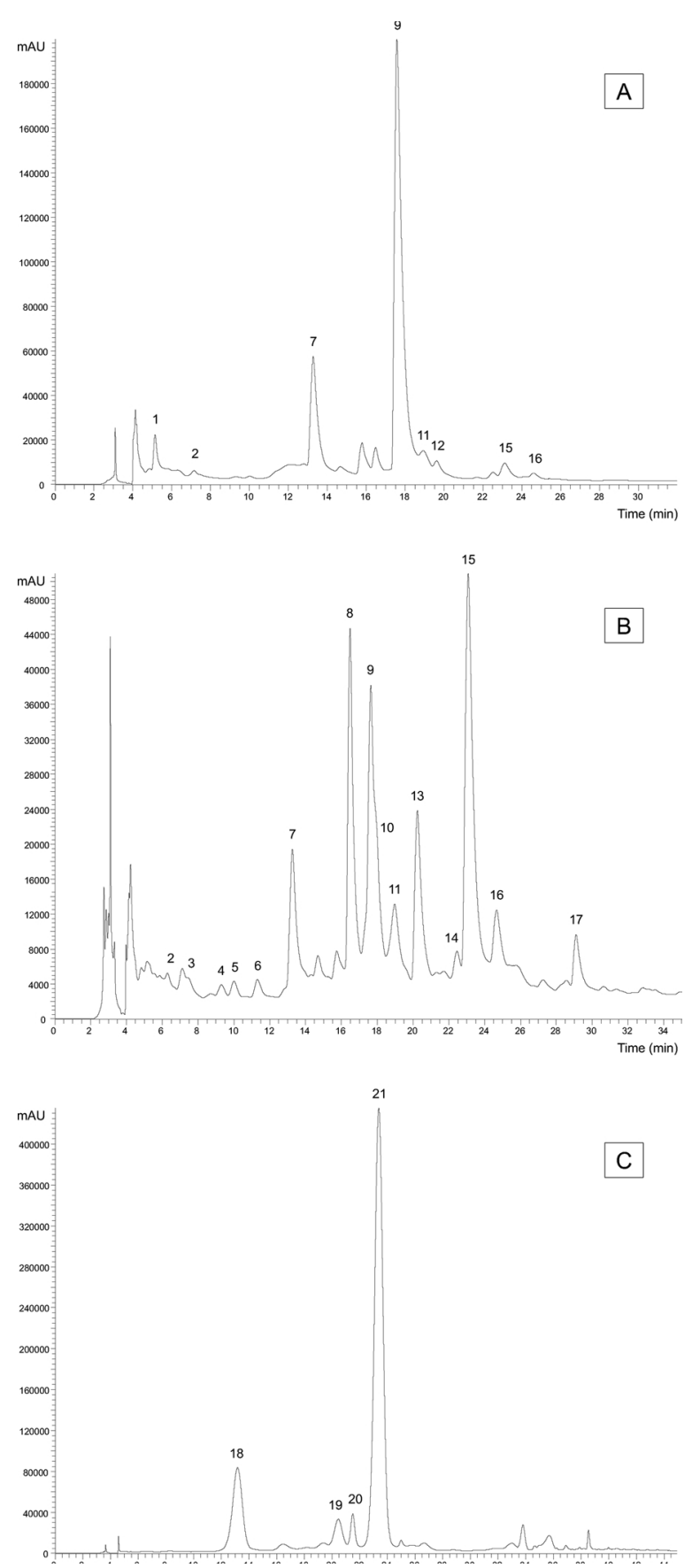

Fig. 1. HPLC phenolic profile of the (A) upper (flowers) and (B) lower (receptacle and involucre) parts of cornflower capitula, recorded at $370 \mathrm{~nm}$; and anthocyanins profile of the flowers, recorded at $520 \mathrm{~nm}$. See Table 2 for peak identification.

hexosyl moiety) and two minor fragments at $\mathrm{m} / \mathrm{z} 449$ (loss of $100 \mathrm{u}$, succinyl moiety) and $m / z 287$ (loss of $162 \mathrm{u}$, hexosyl moiety). Therefore, this compound was tentatively identified as cyanidin-3-O-(6"succinylglucoside)-5-O-glucoside, in accordance with the reports of Escher et al. (2018). This anthocyanin is known to participate in the metal-complexation responsible for the blue colour of the cornflower flowers (Yoshida et al., 2009), and was found in an interestingly high concentration $(15.7 \pm 0.9 \mu \mathrm{g} / \mathrm{g}$ extract). The peak with the shortest retention time (peak 18) presented a pseudomolecular ion $[\mathrm{M}+\mathrm{H}]^{+}$at $m / z 611$, which released a major fragment at $m / z 449$ and a minor one at $m / z 287$, both times due to a loss of $162 \mathrm{u}$, which corresponds to a loss of a two hexosyl moiety. This information led to a tentative identification as cyanidin-3,5-di-O-glucoside. The following peak (number 19) showed a similar fragmentation pattern to compound 21, although instead of a succinyl moiety there was a malonyl. The mass spectral characteristics in combination with the UV data allowed the identification of this compound as cyanidin-3-O-(6"-malonylglucoside)5-O-glucoside. Peak 20 was identified as cyanidin-3-O-glucoside according to the retention time, UV spectra and mass spectral data in comparison with the commercial standard (Table 2).

The total anthocyanins content found in the analysed samples (27 $\pm 1 \mu \mathrm{g} / \mathrm{g}$ extract) highlights the potential of these flowers as a source of natural colorants in the blue range with possible applications in different industrial sectors, including the food, pharmaceutical and cosmeceutical industries.

\subsection{Bioactivities of the hydromethanolic extracts}

\subsubsection{Antioxidant and antihaemolytic activities}

The antioxidant activity of the hydromethanolic extracts prepared from the flowers and non-edible bristly part of the cornflower capitulum has been tested with different in vitro assays, which assured an overview of the antioxidant activity in differing surroundings. The results of the OxHLIA, TBARS formation inhibition and $\beta$-carotene bleaching inhibition assays are presented in Table 3.

The antihaemolytic properties of the extracts were assessed in an $e x$ vivo erythrocytes system by the OxHLIA assay. The haemolysis curves for the extract of the non-edible part of the cornflower capitulum at different concentration obtained by this method are graphically illustrated in Fig. 2, where it is shown that the higher concentrations protect the erythrocyte population from haemolysis for a longer period of time. After application of Eq. (2), the $\Delta t$ values were correlated to the tested extract concentrations, giving the concentration needed to promote a $\Delta$ t haemolysis delay (Takebayashi et al., 2012). In this assay, the $\mathrm{IC}_{50}$ values were given at two $\Delta \mathrm{t}$ because the natural extracts contain different antioxidants capable of interacting with each other and offering protection at different time periods. The extract of the non-edible part showed higher antioxidant and antihaemolytic activity than the one prepared with the edible blue flowers. In the OxHLIA assay, $65 \pm 2 \mu \mathrm{g} / \mathrm{mL}$ and $132 \pm 2 \mu \mathrm{g} / \mathrm{mL}$ were required to protect half of the erythrocyte population from the haemolytic action caused the used oxidative agent for $60 \mathrm{~min}$ and $120 \mathrm{~min}$, respectively, while $193 \pm 9 \mu \mathrm{g} / \mathrm{mL}$ and $356 \pm 12 \mu \mathrm{g} / \mathrm{mL}$ of the flower extract were necessary (Table 3 ). Trolox, the used positive control, provided a higher protection to the erythrocytes membranes than the tested plant extracts, with $\mathrm{IC}_{50}$ values of $20.3 \pm 0.3 \mu \mathrm{g} / \mathrm{mL}$ and $44.18 \pm 0.03 \mu \mathrm{g} / \mathrm{mL}$ at $60 \mathrm{~min}$ and $120 \mathrm{~min}$, respectively. However, Trolox is a pure compound while the plant extracts are complex mixtures of different antioxidant and non-antioxidant compounds. This assay offers test conditions that are very close to the in vivo situation; the erythrocytes are exposed to the oxidation induced by AAPH, but promoted by peroxyl radicals, which are ROS observed in the human body as well (Takebayashi et al., 2012).

The extract of the non-edible part was also more efficient in inhibiting the formation of TBARS (resulting from the oxidation of the brain cell membranes, with consequent formation of malondialdehyde) and the bleaching of $\beta$-carotene (by linoleate free radicals) promoted by the oxidative agents produced in the in vitro reaction system, requiring $137 \pm 8 \mu \mathrm{g} / \mathrm{mL}$ and $18.5 \pm 0.2 \mu \mathrm{g} / \mathrm{mL}$ of extract, respectively. These differences between extracts show the antioxidant potential of the unexplored part of the cornflower capitulum.

\subsubsection{Anti-proliferative activity and hepatotoxicity}

The results for anti-proliferative activity as well as hepatotoxicity of the cornflower extracts are presented in Table 3. The tested samples showed no anti-proliferative activity, with $\mathrm{GI}_{50}$ values higher than $400 \mu \mathrm{g} / \mathrm{mL}$ for all tested cancer cell lines. Interestingly, both extracts had no cytotoxicity against the non-tumour liver primary culture, PLP2 
Table 3

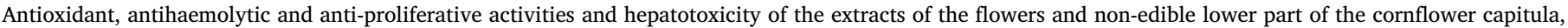
and positive controls (trolox or ellipticine).

\begin{tabular}{|c|c|c|c|c|}
\hline & Flowers & Non-edible part & Positive control & Statistics $^{\mathrm{a}}$ \\
\hline Antioxidant activity ( $E C_{50}$ values, $\mu \mathrm{g} / \mathrm{mL}$ ) & & & Trolox & p-value \\
\hline$\beta$-carotene bleaching inhibition & $20.22 \pm 0.01$ & $18.5 \pm 0.2$ & $0.20 \pm 0.01$ & $<0.001$ \\
\hline TBARS formation inhibition & $321 \pm 40$ & $137 \pm 8$ & $5.8 \pm 0.6$ & 0.001 \\
\hline Antihaemolytic activity $\left(I C_{50}\right.$ values, $\left.\mu \mathrm{g} / \mathrm{mL}\right)$ & & & Trolox & \\
\hline OxHLIA, $\Delta \mathrm{t}=60 \mathrm{~min}$ & $193 \pm 9$ & $65 \pm 2$ & $20.3 \pm 0.3$ & $<0.001$ \\
\hline OxHLIA, $\Delta \mathrm{t}=120 \mathrm{~min}$ & $356 \pm 12$ & $132 \pm 2$ & $44.18 \pm 0.03$ & $<0.001$ \\
\hline Anti-proliferative activity ( $\left(\mathrm{I}_{50}\right.$ values, $\mu \mathrm{g} / \mathrm{mL}$ ) & & & Ellipticine & \\
\hline MCF-7 (breast carcinoma) & $>400$ & $>400$ & $1.21 \pm 0.02$ & - \\
\hline NCI-H460 (non-small cell lung carcinoma) & $>400$ & $>400$ & $1.03 \pm 0.09$ & - \\
\hline HeLa (cervical carcinoma) & $>400$ & $>400$ & $0.9 \pm 0.1$ & - \\
\hline HepG2 (hepatocellular carcinoma) & $>400$ & $>400$ & $1.10 \pm 0.09$ & - \\
\hline Hepatotoxicity ( $\left(\mathrm{II}_{50}\right.$ values, $\mu \mathrm{g} / \mathrm{mL}$ ) & & & Ellipticine & \\
\hline PLP2 & $>400$ & $>400$ & $2.3 \pm 0.2$ & - \\
\hline
\end{tabular}

a Statistical differences $(p<0.05)$ were assessed by applying a two-tailed paired Student's $t$-test.

$\left(\mathrm{GI}_{50}>400 \mu \mathrm{g} / \mathrm{mL}\right)$. These results are in accordance with the previous observations of Pires et al. (2018), and are supported by the study of Escher et al. (2018), which observed no growth inhibition for tumour cells or healthy liver cells with concentrations up to $900 \mu \mathrm{g} / \mathrm{mL}$.

\subsubsection{Antibacterial activity}

The results of the antibacterial activity of the tested extracts are presented in Table 4. The flower extract was active against all the microorganisms tested, while the extract of the non-edible lower part of the capitulum showed no activity $(>20 \mathrm{mg} / \mathrm{mL}$ ) against Klebsiella pneumoniae and Pseudomonas aeruginosa. Both extracts had low activity $(20 \mathrm{mg} / \mathrm{mL})$ against Escherichia coli, Morganella morganii and Proteus mirabilis. In addition, the extracts were generally found to be more active against Gram-positive bacteria, with MICs ranging down to $2.5 \mathrm{mg} / \mathrm{mL}$ for Listeria monocytogenes in case of both extracts and MSSA for the flower extract. The analysis that has been performed with the extracts from a cornflower sample from Portugal showed higher MIC values for Gram-negative bacteria (Pires et al., 2018), thus translating a less antibacterial activity; whereas the activity against Gram-positive bacteria, however, was slightly superior.

As discussed above, the chemical composition of the analysed plant samples presented a certain variation in relation to the data available in the literature, which may justify the results obtained for the bioactivity assays. Moreover, these bioactive properties could also be linked to the bioactive compounds present in both parts of the plant.

\section{Conclusions}

This study focuses on the chemical composition and bioactive potential of the upper (edible flowers) and lower (non-edible receptacle and involucre) parts of the cornflower capitulum. While the flowers have been used in culinary decoration, as ingredient of herbal teas, and for their blue pigmentation, the lower part is a by-product of no commercial value whose bioactive potential, as far as we know, has remained unexplored so far. Chromatographic analyses showed that the flowers are richer in tocopherols ( $\alpha$ and $\gamma$ isoforms), organic acids (citric and succinic acid) and apigenin derivatives (mainly apigenin-7-Oglucuronide-4'-O-(6-O-malonylglucoside)), while the non-edible parts are richer in quinic, succinic and syringic acids. Four cyanidin derivative anthocyanins were found in the capitulum flowers, with cyanidin3-O-(6"-succinylglucoside)-5-O-glucoside as the main compound. The antioxidant activity assays showed that the extract of the non-edible part was more efficient in inhibiting the formation of TBARS, the bleaching of $\beta$-carotene, and the haemolysis of the erythrocytes membrane. The extracts were generally more effective against Gram-positive bacteria, such as Listeria monocytogenes and methicillin-susceptible Staphylococcus aureus (MSSA), and had no cytotoxicity against non-tumour liver PLP2 cells. These results indicated that, while flowers are a potential source of tocopherols, organic acids and cyanidin derivatives, the lower part of the capitulum presents antioxidant and antibacterial properties to be exploited in different food or pharmaceutical formulations.

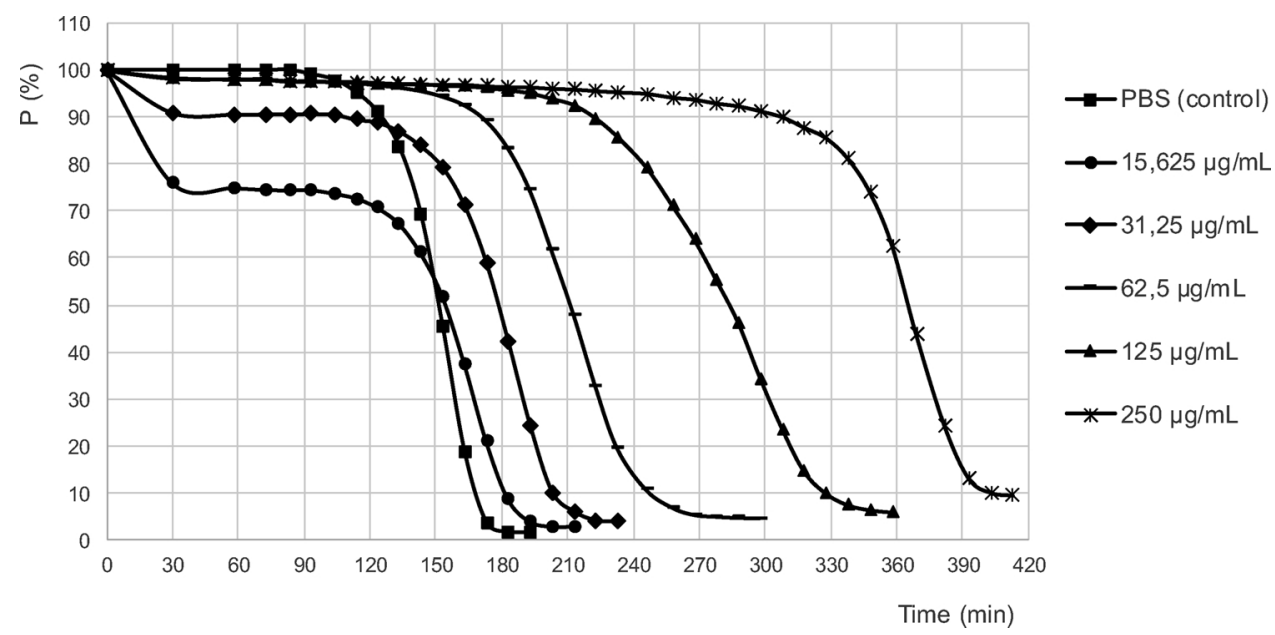

Fig. 2. Haemolysis curves for the extract of the non-edible lower part of the cornflower capitulum at different concentrations, obtained by the OxHLIA assay. 
Table 4

Antibacterial activity (MIC values, $\mathrm{mg} / \mathrm{mL}$ ) of the extracts of the flowers and non-edible lower part of the cornflower capitula, and positive controls (ampicillin, imipenem and vancomycin).

\begin{tabular}{|c|c|c|c|c|c|}
\hline & Flowers & Non-edible part & Ampicillin & Imipenem & Vancomycin \\
\hline \multicolumn{6}{|l|}{ Gram-negative bacteria } \\
\hline Escherichia coli & 20 & 20 & $<0.15$ & $<0.078$ & $\mathrm{nt}$ \\
\hline Klebsiella pneumoniae & 20 & $>20$ & 10 & $<0.078$ & $\mathrm{nt}$ \\
\hline Pseudomonas aeruginosa & 10 & $>20$ & $>20$ & 0.5 & nt \\
\hline Proteus mirabilis & 10 & 20 & $<0.15$ & $<0.078$ & $\mathrm{nt}$ \\
\hline \multicolumn{6}{|l|}{ Gram-positive bacteria } \\
\hline Enterococcus faecalis & 5 & 5 & $<0.15$ & nt & $<0.078$ \\
\hline MSSA & 2.5 & 5 & $<0.15$ & nt & 0.25 \\
\hline
\end{tabular}

nt: not tested.

\section{Acknowledgements}

The authors are grateful to the Foundation for Science and Technology (FCT, Portugal) and FEDER under Programme PT2020 for financial support to CIMO (UID/AGR/00690/2013); to FCT for the grants of C.L. Roriz (SFRH/BD/129551/2017) and C. Pereira (SFRH/ BPD/122650/2016) (awarded under the Programa Operacional Capital Humano (POCH) supported by the European Social Fund and National Funds of MCTES (Ministério da Ciência, Tecnologia e Ensino Superior), and the research contracts of J. Pinela (Project AllNatt, POCI-01-0145FEDER-030463) and L. Barros. This work is also funded by the European Regional Development Fund (ERDF) through the Regional Operational Program North 2020, within the scope of Project NORTE01-0145-FEDER-023289: DeCodE and project Mobilizador Norte-010247-FEDER-024479: ValorNatural ${ }^{\circledR}$; and FEDER-Interreg EspañaPortugal through the project 0377_Iberphenol_6_E.

\section{References}

Barros, L., Pereira, E., Calhelha, R.C., Dueñas, M., Carvalho, A.M., Santos-Buelga, C., Ferreira, I.C.F.R., 2013. Bioactivity and chemical characterization in hydrophilic and lipophilic compounds of Chenopodium ambrosioides L. J. Funct. Foods 5, 1732-1740.

Bessada, S.M.F., Barreira, J.C.M., Barros, L., Ferreira, I.C.F.R., Oliveira, M.B.P.P., 2016. Phenolic profile and antioxidant activity of Coleostephus myconis (L.) Rchb.f.: an underexploited and highly disseminated species. Ind. Crops Prod. 89, 45-51.

Escher, G.B., Santos, J.S., Rosso, N.D., Marques, M.B., Azevedo, L., do Carmo, M.A.V., Daguer, H., Molognoni, L., Prado-Silva, L., do, Sant'Ana, A.S., da Silva, M.C., Granato, D., 2018. Chemical study, antioxidant, anti-hypertensive, and cytotoxic/cytoprotective activities of Centaurea cyanus L. petals aqueous extract. Food Chem. Toxicol. 118, 439-453.

Evans, B.C., Nelson, C.E., Yu, S.S., Beavers, K.R., Kim, A.J., Li, H., Nelson, H.M., Giorgio, T.D., Duvall, C.L., 2013. Ex vivo red blood cell hemolysis assay for the evaluation of pH-responsive endosomolytic agents for cytosolic delivery of biomacromolecular drugs. J. Vis. Exp. e50166.

Garbacki, N., Gloaguen, V., Damas, J., Bodart, P., Tits, M., Angenot, L., 1999. Anti-inflammatory and immunological effects of Centaurea cyanus flower-heads. J. Ethnopharmacol. 68, 235-241.

Ghnimi, S., Al-Shibli, M., Al-Yammahi, H.R., Al-Dhaheri, A., Al-Jaberi, F., Jobe, B., Kamal-Eldin, A., 2018. Reducing sugars, organic acids, size, color, and texture of 21 Emirati date fruit varieties (Phoenix dactylifera L.). NFS J. 12, 1-10.

Gonçalves, G.A., Soares, A.A., Correa, R.C.G., Barros, L., Haminiuk, C.W.I., Peralta, R.M., Ferreira, I.C.F.R., Bracht, A., 2017. Merlot grape pomace hydroalcoholic extract improves the oxidative and inflammatory states of rats with adjuvant-induced arthritis. J. Funct. Foods 33, 408-418.

Hellwig, F.H., 2004. Centaureinae (Asteraceae) in the Mediterranean - history of ecogeographical radiation. Plant Syst. Evol. 246, 137-162.

Igamberdiev, A.U., Bykova, N.V., 2018. Role of organic acids in the integration of cellular redox metabolism and mediation of redox signalling in photosynthetic tissues of higher plants. Free Radic. Biol. Med. 122, 74-85.

Kondo, T., Ueda, M., Isobe, M., Goto, T., 1998. A new molecular mechanism of blue color development with protocyanin, a supramolecular pigment from cornflower, Centaurea cyanus. Tetrahedron Lett. 39, 8307-8310.

López-Bucio, J., Nieto-Jacobo, M.F., Ramírez-Rodríguez, V., Herrera-Estrella, L., 2000. Organic acid metabolism in plants: from adaptive physiology to transgenic varieties for cultivation in extreme soils. Plant Sci. 160, 1-13.

Marian, E., Grațiela Vicaș, L., Tunde, J., Mureșan, M., Stan, R.L., Sevastre, B., Diaconeasa, Z., Ionescu, C., Hangan, A.C., 2017. A comparative study on the biologic activity of
Centaurea cyanus versus Calendula officinalis. Farmacia 65, 940-946.

Martins, N., Barros, L., Ferreira, I.C.F.R., 2016. In vivo antioxidant activity of phenolic compounds: facts and gaps. Trends Food Sci. Technol. 48, 1-12.

Naso, L.G., Valcarcel, M., Roura-Ferrer, M., Kortazar, D., Salado, C., Lezama, L., Rojo, T., González-Baró, A.C., Williams, P.A.M., Ferrer, E.G., 2014. Promising antioxidant and anticancer (human breast cancer) oxidovanadium(IV) complex of chlorogenic acid. Synthesis, characterization and spectroscopic examination on the transport mechanism with bovine serum albumin. J. Inorg. Biochem. 135, 86-99.

NIH, 2018. Vitamin E - Health Professional Fact Sheet [WWW Document]. (accessed 8.1.18). https://ods.od.nih.gov/factsheets/VitaminE-HealthProfessional/.

Ornelas-Paz, J., de, J., Yahia, E.M., Ramírez-Bustamante, N., Pérez-Martínez, J.D., Escalante-Minakata, M., del, P., Ibarra-Junquera, V., Acosta-Muñiz, C., GuerreroPrieto, V., Ochoa-Reyes, E., 2013. Physical attributes and chemical composition of organic strawberry fruit (Fragaria $\mathrm{x}$ ananassa Duch, Cv. Albion) at six stages of ripening. Food Chem. 138, 372-381.

Pereira, C., Barros, L., Carvalho, A.M., Ferreira, I.C.F.R., 2013a. Use of UFLC-PDA for the analysis of organic acids in thirty-five species of food and medicinal plants. Food Anal. Methods 6, 1337-1344.

Pereira, C., Calhelha, R.C., Barros, L., Ferreira, I.C.F.R., 2013b. Antioxidant properties, anti-hepatocellular carcinoma activity and hepatotoxicity of artichoke, milk thistle and borututu. Ind. Crops Prod. 49, 61-65.

Pinela, J., Barros, L., Carvalho, A.M., Ferreira, I.C.F.R., 2012a. Nutritional composition and antioxidant activity of four tomato (Lycopersicon esculentum L.) farmer' varieties in Northeastern Portugal homegardens. Food Chem. Toxicol. 50, 829-834.

Pinela, J., Barros, L., Dueñas, M., Carvalho, A.M., Santos-Buelga, C., Ferreira, I.C.F.R., 2012b. Antioxidant activity, ascorbic acid, phenolic compounds and sugars of wild and commercialTuberaria lignosa samples: Effects of drying and oral preparation methods. Food Chem. 135, 1028-1035.

Pires, T.C.S.P., Dias, M.I., Barros, L., Calhelha, R.C., Alves, M.J., Oliveira, M.B.P.P., Santos-Buelga, C., Ferreira, I.C.F.R., 2018, Edible flowers as sources of phenolic compounds with bioactive potential. Food Res. Int. 105, 580-588.

Pires, T.C.S.P., Dias, M.I., Barros, L., Ferreira, I.C.F.R., 2017. Nutritional and chemica characterization of edible petals and corresponding infusions: valorization as new food ingredients. Food Chem. 220, 337-343.

Renaud, S., de Lorgeril, M., 1992. Wine, alcohol, platelets, and the French paradox for coronary heart disease. Lancet (Lond. Engl.) 339, 1523-1526.

Reuter, S., Gupta, S.C., Chaturvedi, M.M., Aggarwal, B.B., 2010. Oxidative stress, inflammation, and cancer: how are they linked? Free Radic. Biol. Med. 49, 1603-1616.

Rop, O., Mlcek, J., Jurikova, T., Neugebauerova, J., Vabkova, J., 2012. Edible flowers - a new promising source of mineral elements in human nutrition. Molecules 17, 6672-6683.

Roriz, C.L., Barreira, J.C.M., Morales, P., Barros, L., Ferreira, I.C.F.R., 2018. Gomphrena globosa L. As a novel source of food-grade betacyanins: incorporation in ice-cream and comparison with beet-root extracts and commercial betalains. LWT 92, 101-107.

Takebayashi, J., Iwahashi, N., Ishimi, Y., Tai, A., 2012. Development of a simple 96-well plate method for evaluation of antioxidant activity based on the oxidative haemolysis inhibition assay (OxHLIA). Food Chem. 134, 606-610.

Takeda, K., 2006. Blue metal complex pigments involved in blue flower color. Proc. Jpn. Acad. Ser. B: Phys. Biol. Sci. 82, 142-154.

Valko, M., Leibfritz, D., Moncol, J., Cronin, M.T.D., Mazur, M., Telser, J., 2007. Free radicals and antioxidants in normal physiological functions and human disease. Int. J. Biochem. Cell Biol. 39, 44-84.

Vaz, J.A., Heleno, S.A., Martins, A., Almeida, G.M., Vasconcelos, M.H., Ferreira, I.C.F.R., 2010. Wild mushrooms Clitocybe alexandri and Lepista inversa: in vitro antioxidant activity and growth inhibition of human tumour cell lines. Food Chem. Toxicol. 48, 2881-2884.

Vigani, G., Pii, Y., Celletti, S., Maver, M., Mimmo, T., Cesco, S., Astolfi, S., 2018. Mitochondria dysfunctions under Fe and S deficiency: is citric acid involved in the regulation of adaptive responses? Plant Physiol. Biochem. 126, 86-96.

Yoshida, K., Mori, M., Kondo, T., 2009. Blue flower color development by anthocyanins: from chemical structure to cell physiology. Nat. Prod. Rep. 26, 884. 